\title{
Comunicadoras Indígenas e Afrodescendentes Latino-Americanas: Sororidade e Identidades
}

\author{
Lizia de Oliveira Carvalho' (iD 0000-0003-3783-9646 \\ Nidia Rosmery Bustillos Rodriguez ${ }^{2}$ (iD 0000-0002-4302-9407 \\ 'Universidade Federal de Goiás, Núcleo de Direitos Humanos, Programa de Pós- \\ Graduação em Direitos Humanos, Goiânia, GO, Brasil. \\ 74690-900 - direitoshumanosufg@gmail.com \\ ${ }^{2}$ Institut Universitaire D'etudes du Développement, Genève, Suisse. \\ iued@unige.ch
}

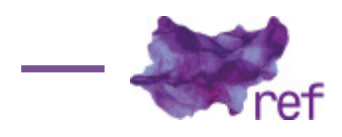

Resumo: Este artigo irá relacionar mobilizações e narrativas de comunicadoras indígenas sob o olhar do feminismo decolonial. Foca na maneira em que as ações comunicativas de mulheres indígenas do México e América Central contribuem para que sua participação política se entrelace com os esforços de efetivação dos direitos humanos. Pretende-se, com o cruzamento metodológico de fontes e perspectivas teóricas locais, demonstrar que a utilização de hipermídias das mulheres latino-americanas que, na ampla divulgação em diversas redes sociais, tem sido importante para se alimentar mecanismos para que construam um espaço de mobilização social e política. E, por elas, viver e aprender com o emancipatório feminismo decolonial: que atua além do hegemônico e consonante com as localidades e desejos coletivos. Além disso, pretende-se discutir a relevância de encontros de comunicadoras para a troca de experiências para a reafirmação de suas identidades, interseccionadas em suas afinidades. Palavras-chave: Feminismo decolonial; hipermídia; comunicadoras indígenas

Latin American Indigenous and Afro-Descendant Communicators: Sorority and Identities Abstract: This article will relate mobilizations and narratives of indigenous communicators under the eyes of decolonial feminism. It focuses on how the communicative actions of indigenous women in Mexico and Central America help their political participation to intertwine with efforts to realize human rights. With the methodological cross-referencing of local sources and theoretical perspectives, it is intended to demonstrate that the use of hypermedia by Latin American women and in the wide dissemination in various social networks has been important for feeding mechanisms to build a space for mobilization Social and political. And for them, living and learning with the emancipatory decolonial feminism: that acts beyond the hegemonic and consonant with localities and collective desires. In addition, it is intended to discuss the relevance of meetings of communicators for the exchange of experiences for the reaffirmation of their identities, intersected in their affinities.

Keywords: Decolonial feminism; hypermedia; indigenous communicators

\section{Introdução}

Este artigo caracteriza-se pela abordagem interdisciplinar em que as construções teóricas sumarizam e criam perspectivas científicas idiossincráticas que, destacadas em seus nichos prévios de atuação, não explicariam as figuras e respectivos elementos emergentes.

Para garantir que haja um diálogo ampliado e a consideração de variáveis interpretativas, a bricolage de fontes secundárias prioriza o olhar de nossa Améfrica Ladina, ' que compartilha a

\footnotetext{
' A categoria Amefricanidade, cunhada por Lélia Gonzalez (1988), trata de um novo olhar na perspectiva da formação histórico-cultural do Brasil e do continente americano que, por questões geográficas e de ordem do
} 
exegese da ineficácia da aplicação dos Direitos Humanos onde as cosmologias não reconhecem os anseios atrelados a noções ocidentais como a dignidade ou liberdade.

Boaventura de Sousa SANTOS (2009) sustenta a tese de que a universalidade é uma questão particular e específica da cultura ocidental, fazendo com que os direitos humanos não se tornem universais na sua aplicação. Enquanto forem concebidos como universais, os direitos humanos tenderão a operar de-cima-para-baixo (SANTOS, 2009, p. 10-18). Sendo assim, de acordo com o pensador português, para serem legítimos, os direitos humanos devem ser reconceitualizados como multiculturais.

Adentremos essa inferência. A multiculturalidade, de acordo com Vera CANDAU (1998, p. 45-57), pode ter a abordagem descritiva (ou algo inerente à atualidade e específico às localidades) ou prescritiva (que, além de um dado da realidade, projeta sentidos e ações ligadas à própria dinâmica social). Derivadas destas, distingue três perspectivas do fenômeno: o multiculturalismo assimilacionista (que preconiza uma universalidade monocultural, em que está implícita a necessidade de substituição das culturas e suas manifestações em razão de um conjunto superior de valores e ordens); diferencialista (ou apartheids socioculturais, em que se reconhece a diferença e suas associações são aprofundadas), como é percebido nas tensões educacionais recentes no Brasil, corporificadas nas causas e efeitos das políticas de ação afirmativa no acesso à universidade; e o interativo, ou intercultural, que reconhece a fluidez das identidades e sua hibridização, reage, compreende as representações e conflitos de forma crítica e estrategicamente engajada para alcançar uma justiça social. Está alinhada ao multiculturalismo crítico de Peter MCLAREN (1997). Por isso, caracterizaremos a premissa da interculturalidade ou multiculturalidade crítica, por reconhecer previamente os atores como protagonistas do processo.

Ao se conviver em sociedade, os seres humanos se agrupam por interesses comuns, buscando solucionar questões pertinentes a esse grupo. Fomos ensinados que o marco de cidadania e luta por direitos humanos se inicia com as revoluções Inglesa, Francesa e Americana, direcionando o Olhar para eventos europeus. Omitem-se em importância os movimentos contínuos de resistência, nascentes no próprio momento da dominação. Referimo-nos aqui ao fenômeno da colonialidade e sua antítese, a decolonialidade.

Júlia ALMEIDA (201 1, p. 1-10) reitera que colonialidade não é a colonização em si, mas a lógica que passa a ser fundamental a partir do século XVI, com a consolidação das interações no sistema atlântico. Com o mercantilismo, emerge um padrão de exploração e dominação que conecta conquista de territórios, uma hierarquização racial, o controle da força de trabalho, do gênero e sexualidade, ambiente e a produção de conhecimento. Esse modelo de poder - a colonialidade, termo apresentado por Aníbal Quijano - é abalizado por uma afirmada superioridade étnica e cognitiva do colonizador com relação ao colonizado (Santiago CASTROGÓMEZ, 2006, p. 28). Essa suposta superioridade legitima a missão civilizatória do ocidente e suas violentas manifestações. Por meio dela são apontados como outros, os negros, índios e mestiços, inferiorizados e passíveis de exploração e opressão (ALMEIDA, 2011).

O papel subalterno delegado às mulheres na colonialidade provocou reações, historicamente, dos espaços domésticos aos públicos. Os estudos feministas, bem como sua mobilização, contribuem muito para que as discrepâncias entre homens e mulheres sejam expostas e publicizadas, denunciando que os espaços de influência ocidental ainda têm uma longa estrada ao alcance da equidade de gênero. Os indicadores relacionados à violência doméstica denunciada (sem considerar o que foge aos registros do Estado) denotam a urgência da movimentação feminista.

Muitas mulheres indígenas na atualidade estão sujeitas, assim como mulheres não indígenas, a problemas de violência doméstica, exclusão dos espaços de poder, dificuldades para participação social e política e desenvolvem tripla jornada de trabalho. Ou seja, os padrões de raízes patriarcais as afetam, quase como as não indígenas. Porém, os indicadores precisam ser redimensionados porque as relações são distintas. Mas não se pode negar que há influência da colonialidade nas relações entre homens e mulheres em muitas comunidades, assim como reações de entre-lugares discursivos (Homi K. BHABHA, 2003).

Acompanhando e tensionando o encontro nas fronteiras, mulheres indígenas em toda Améfrica Ladina têm igualmente participado de debates sobre a violência doméstica, as dificuldades em sua participação pública-política, as desigualdades de gênero em suas organizações, comunidades e famílias. De maneira representativa, são porta-vozes dos riscos à sobrevivência de sua identidade cultural e sociedades, bem como do reconhecimento dos papéis que desempenham (Diane REED, 1995). Exigem novas formas de participação em que não sejam excluídas e discriminadas (ONIC, 1994).

inconsciente permeadas por um pensamento exclusivamente europeu, não são o que geralmente se afirma. Ao invés disso, é uma América Africana "cuja latinidade, por inexistente, teve trocado o $t$ pelo $d$ para, aí sim, ter o seu nome assumido com todas as letras: Améfrica Ladina" (GONZALEZ, Lélia. "A categoria político-cultural de amefricanidade". Tempo Brasileiro, n. 92/93, p. 69-82, janeiro/junho 1988). 
O fenômeno do feminismo indígena deve-se ao aumento do nível de escolaridade formal das mulheres indígenas, às aberturas à sua participação, à possibilidade de organizarem-se e, por conseguinte, a um aumento de sua presença nas estruturas organizacionais, por demanda de organismos internacionais para a incorporação da perspectiva de gênero nos projetos que as organizações indígenas controlam. Algumas iniciativas internacionais, especialmente não governamentais, de efetivação dos direitos humanos, têm sido partícipes em seu fomento e divulgação. Além disso, há uma crescente incursão na política partidária (Georgina Méndez TORRES, 2009).

Maria LUGONES (2012), autora argentina que baliza análises muito pertinentes e referendadas sobre a emergência da movimentação de mulheres e sua articulação, assevera que a colonialidade se manifesta nas ideias de teorias feministas hegemônicas, pois são ideias eurocentradas e universalizadas de emancipação da mulher. Desconsideram as diferenças essenciais que existem entre as mulheres brancas, as mulheres negras, latinas, índias e suas opressões. Sendo assim, essas teorias não são representativas das necessidades das mulheres não brancas, portanto, são fontes de dominação e propagação da colonialidade.

\begin{abstract}
Sobre as feministas hegemônicas, as lutas feministas foram construídas considerando o conceito 'mulher' como universal, como se todas as mulheres fossem brancas, tivessem as mesmas necessidades e sofressem as mesmas opressões. Assim, as mulheres que não se encaixavam nas descrições do que se concebia como 'mulher' não eram vistas ou eram vistas como era conveniente para o sistema eurocêntrico. As mulheres colonizadas tinham status muito diferentes das mulheres brancas, antes e depois da colonização. Para Lugones, as feministas brancas viam uma ligação de todas as mulheres pelo gênero, que eliminava a necessidade de compreender também a categoria raça. No entanto, as mulheres colonizadas e não-brancas tinham representações sociais específicas que não cabiam no conceito de mulher dos feminismos hegemônicos (Letícia Otero DIAS, 2014, p. 11).
\end{abstract}

A própria manutenção de um feminismo universal dita as possibilidades, logo, as particularidades dos grupos negados. Dessa forma, lutas específicas se perdem e ficam do outro lado da linha - o colonial -, menos visíveis ainda por serem mantidas e desconsideradas num espaço configurado como inexistente. Por este lugar, a construção de um feminismo de resistência à dominação, que se aprofunde em suas próprias verdades, e que seja construído por mulheres que vivem no entre-lugar e que sofrem diversas opressões conectadas, que interseccione as múltiplas opressões, de raça, classe e gênero, que represente essas mulheres e que seja um contraponto de resistência múltipla a opressões múltiplas. A despatriarcalização só é possível se houver a descolonização do saber e do ser a partir de um feminismo decolonial, rompido com a universalidade dos feminismos hegemônicos (LUGONES, 2012, p. 1).

\title{
A sociedade da informação, mulheres indígenas e tecnologias de informação e comunicação (TICs) ${ }^{2}$
}

Todos os povos têm tido a comunicação como um elemento vital para sua sobrevivência. Desde os antigos caminhos da rota da seda, o hapacÑan andino, a humanidade tem buscado vincular territórios e povos para exercer seu domínio ou melhorar o contato. No ocidente, o surgimento e o uso massivo das TICs (comunicação e conhecimento) são ocasionados pelos fluxos globais cada vez mais intensos, não somente no âmbito econômico e nas redes de consumo, mas também cultural. Como movimento insurgente à priorização de discursos de crescimento, aproveita no fomento a um diálogo tecnológico e biotecnológico, que embora desigual por estar inserido nas relações desiguais entre norte e sul, tem produzido uma aproximação e agilidade nas articulações. Com o acesso às TICs, as fronteiras desaparecem nas relações pessoais e já não se fala de um centro, isolado, sem uma rede que compreende e produz outras relações, imprevistas ou não (Nidia BUSTILLOS, 2004).

Segundo Anthony Giddens (apud BUSTILLOS, 2004), as TICs enquadradas dentro da noção de tempo e espaço da modernidade são as que contribuem a uma ação a distância e não se sujeitam a territorialidades nem a tempos específicos. Algo que deve ser considerado é que "todos os ordenamentos dos sucessos significativos perdem seu ritmo cronológico interno e ficam dispostos em sequências temporais que dependem do contexto social de sua utilização [...] é uma cultura, ao mesmo tempo, do eterno e o efêmero" (Manuel CASTELLS, 1997, p. 97). É necessário estar atentas ao fato de que, embora grande parte dos websites esteja hospedada no Norte, os conteúdos culturais respondem a monoculturas de transnacionais poderosas que impregnam com seu tino as diversas manifestações culturais do planeta (Susan HAWTHORNE, 1999).

\footnotetext{
2 "Durante muitos anos, falava-se apenas no computador. Depois, com a proeminência que os periféricos começaram a ter, começou a falar-se em novas tecnologias de informação (NTI). Com a associação entre informática em telecomunicações, generalizou-se o termo Tecnologias de Informação e Comunicação (TIC)" (PONTE, João Pedro da. "Tecnologias de informação e comunicação na formação deprofessores: Que desafios?". Revista Ibero-Americana de Educación, n. 24, p. 63-90, set./dez. 2000).
} 
Na aldeia global, as TICs exacerbam as diferenças criadas com respeito aos padrões históricos de dominação e iniquidade econômica; a divisão se dá não somente entre ricos e pobres, mas também em quem tem informação de decodificação e codificação destas tecnologias e os que carecem dela, uma variável que interfere na rapidez ou lentidão sobre o manejo e acesso à informação e conhecimento armazenados em grandes bases de dados. A informação e tempo se invertem rapidamente e parecem que são muito mais importantes que a sabedoria, a capacidade sensível de interpretar os dados fora de tabulações generalizantes (Sohail S. INAYATULLAH; Ivana MILOJEVIC, 1999).

As comunidades tradicionais mudam seus padrões de vida movidas por processos acelerados de migração, de acesso à eletricidade, televisão e telefonia móvel. Embora as corporações se aproximem aos grupos de povos indígenas, o fazem dentro da racionalidade que instrumentaliza as ações em seu favor, não para alcançar um fluxo comunicativo horizontal e inclusivo (Sergio González MIRANDA, 1999). Os povos indígenas enfrentam processos de perda de linguagem e território e apropriam-se das TICs como instrumentos que podem ajudá-los a melhorar sua situação na sociedade, especialmente em usos educativos. Gera-se a pretensão de que a aprendizagem de um ofício ou programa computacional abrirá as portas para a aceitação dos habitantes das comunidades distantes dentro de uma sociedade que é basicamente excludente, o que tem levado muitas vezes a à ceitação cega, nas comunidades rurais, de todas as propostas desenvolvimentistas que vêm de fora (Javier MONROE; Fabricio ARENAS, 2003) porque esta sociedade, embora alardeada como desenvolvida tecnologicamente, tem por contrapartida um subdesenvolvimento social que é comparativamente imenso em relação aos privilegiados, segundo Manuel Castells (1997).

Por um lado, a globalização busca a homogeneização, mas deve, ao mesmo tempo, aceitar e coabitar com um conjunto de culturas diferenciadas. "Neste sentido a globalização abriga em seu centro a própria diferenciação inerente à modernidade" (Renato ORTIZ, 1995).

A exclusão social também se relaciona com o desenvolvimento das TICs e a sociedade da informação, dado que os ganhos maiores são dos elaboradores dos programas, gerenciadores das organizações e controladores da informação-chave; a monopolização de pessoas com qualificação especial (high skilled) inoportuniza grandes grupos sem oportunidade de acesso a essa formação que, logo, são marginalizados dos benefícios gerados na sociedade em rede, que, por seu tempo, perde sua capacidade analítica de compreensão das próprias realidades locais. Esta exclusão faz com que só os considerados 'qualificados' elaborem propostas para os 'não qualificados', reproduzindo, desta maneira, as relações de poder e dominação. A exclusão não consiste tão somente na marginalização ou na não integração dos indivíduos no sistema, que, embora partícipes, não são tomados em conta como corpo decisório porque não possuem as condições mínimas para serem considerados (Niklas LUHMANN, 1995).

A inovação, uma das mais essenciais alegadas características da sociedade em rede, notadamente associada à produtividade, exige que os processos educativos associados se alimentem de informação e conhecimento (CASTELLS, 1998a). É imperativo considerar que há uma pressão para que as comunidades rurais indígenas tenham que produzir e competir inovadoramente, mas não possuem o acesso requerido à informação adequada, rápida e de uma cadeia de pessoas que manejem e processem-na, para estar em igualdade de condições de visibilidade ou, ao menos, para poder neutralizar propostas que não levam em consideração sua identidade cultural. As batalhas culturais são as batalhas de poder na era da informação. O poder, como capacidade de impor a conduta, reside nas redes de intercâmbio de informação e de manipulação dos símbolos, que relacionam atores sociais, as instituições e os movimentos culturais através de ícones, portavozes e amplificações intelectuais (CASTELLS, 1998b). A manifestação do poder nas sociedades da informação reside nos códigos de informação e nas imagens de representação em torno das quais as sociedades se organizam, bem como suas instituições e como as pessoas constroem suas vidas e decidem suas condutas. O constructo deste poder na interpretação das pessoas retorna, ao mesmo tempo, identificável e difuso (CASTELLS, 1998a).

A sociedade em rede sustenta três grandes identidades, segundo Castells (1998a): a identidade legitimadora, introduzida por instituições dominantes da sociedade para manter o poder estabelecido; a identidade de resistência, que corresponde a atores sociais cuja posição que ocupam é desvalorizada em relação com a lógica dominante e que exerce resistência para poder se manter, apresentando princípios que são contrários ao que manejam os dominantes; e a identidade-projeto, que consiste em atores sociais que usam, como base, os materiais culturais de que dispõem, construindo uma nova identidade que redefine sua posição na sociedade. Ao fazer isto, se expõem não somente à mudança, mas também à transformação de toda a estrutura social, ato que produz sujeitos, mas sujeitos entendidos como atores sociais coletivos. Para o autor, a importância das identidades de resistência é crucial na sociedade em rede, pois pode servir de fundamento para que se gerem identidades-projeto e, assim, reconstruir uma sociedade civil nova e um novo Estado.

Ciente destas implicações, em 1998, em Amsterdam, um grupo de mulheres líderes indígenas formula o Manifesto Indígena durante a Conferência Mundial Know How de Acesso à Informação 
às Mulheres, que denuncia: "deveríamos fazer esforços acordados para influenciar nas políticas de comunicação para salvaguardar os direitos dos povos indígenas. Os povos indígenas estão ameaçados e correm o risco de perder sua identidade, sua cultura e o acesso aos recursos" (ATRIA, 1998). Em 2003, durante a reunião da Cúpula da Informação realizada em Genebra, a discussão girou em torno de preservação do patrimônio cultural, um elemento crucial da identidade pessoal e o conhecimento de si mesmo, que são a conexão de uma comunidade com seu passado. Dentre os compromissos firmados acerca de suas reflexões, a sociedade da informação deveria aproveitar e preservar o patrimônio cultural para o futuro, para o qual utilizará todos os métodos adequados, entre outros, a digitalização, que também abre espaço para outros portfólios de salvaguarda que não sejam necessariamente a linguagem escrita (ONU, 2003).

Durante os anos 2000, 2002 e 2004, duas investigações se empenharam em avaliar em que medida as TICs poderiam contribuir para o empoderamento das mulheres e povos indígenas, centrando a investigação no desenho de uma proposta de apropriação da informação que contemple não somente o acesso à informação, mas o estímulo de capacidades para a negociação, a fim de poder encontrar alternativas para a emancipação como comunidades indígenas na Bolívia (BUSTILLOS, 2002; 2004).

No ano de 2005, no contexto da Conferência Know How realizada na Cidade do México, as abordagens que se realizaram com mulheres líderes indígenas em respeito ao uso das TICs foram que estas reforçam o trabalho ativo para denunciar a situação dos povos e mulheres indígenas. Ao serem usadas como ferramentas estratégicas, podem potencializar o trabalho das comunidades e, em particular, o trabalho das mulheres, na denúncia de violações, tratar de visões específicas sobre temas como o de saúde, direitos humanos, entre outros. E, principalmente, que se estas relações não são neutras, deveriam usar as TICs de maneira pertinente, adequando-as às realidades específicas. De outra maneira, as comunidades e as mulheres indígenas continuaram sendo grupo meta de projetos de desenvolvimento pensado por tecnocratas.

As mulheres indígenas aproveitam as brechas digitais à sua maneira e identificam diversos fatores como limitantes. Um deles é o acesso e o custo dos equipamentos, que continuam sendo proibitivos para muitas delas; da mesma maneira os processos de capacitação, que são inadequados com respeito à sua realidade sociocultural; ainda, o machismo ou o desinteresse nas novas tecnologias e a falta de atenção à necessidade de uso das línguas locais. Muitas vezes, o uso da informação se limita ao e-mail: não existe tempo para aprender o uso das TICs com a profundidade que permita conhecer outras ferramentas, criar e adaptá-las às suas demandas, além de existir um medo imputado da linguagem técnica, até porque geralmente os homens são os que monopolizam o uso dos computadores nas organizações.

Os desafios são vários. O primeiro problema é o machismo da cultura tecnológica, suportado pelo racismo da economia mundial. Existe uma necessidade de processos de informação e acompanhamento que facilitem os contatos virtuais. Além disso, é necessário priorizar a comunicação oral e o uso de videoconferências pode ser altamente positivo no contexto de tradição oral existente. Outra sugestão foi a criação de uma lista de recursos sobre mulheres indígenas na rede. Algo mínimo que sirva às pessoas e às mulheres interessadas em se educar em sua realidade e temáticas com mais afinidade e interesse.

De acordo com Nidia Bustillos, indicou-se que a incorporação das TIC ao trabalho que realizam as irmãs indígenas permitiu ter voz e mudar as situações passadas em que estiveram isoladas e invisibilizadas diante dos demais. A utilização destes recursos continua sendo um desafio para as irmãs indígenas, entretanto, o caminho para alcançar a democratização da informação está sendo percorrido por elas.

Para concluir estas reflexões e investigações, as TICs permitem recriar espaços físicos e virtuais para o fortalecimento do processo de integração territorial, por meio da prestação de serviços de comunicação rápida, através da internet. Facilitam intercâmbios para fortalecer a economia local e regional, pelo apoio à produção, com a informação pertinente de mercado, saúde, informação jurídica, entre outros. Neste espaço se filtra e centraliza a informação feita sob medida, o rol de apoio com informação sobre a história da comunidade, sobre Abya-Yala e a espiritualidade (BUSTILLOS, 2004).

Entretanto, existem elementos subjacentes que correspondem à ordem simbólica. Se abordagens da história, da concepção da realidade são geradas desde sistemas que sustentam valores muito diferentes, então, para transformar a realidade de exclusão que sofrem as comunidades indígenas em todos os níveis, faz-se necessário repensar não somente o comunicativo, mas, sobretudo, as bases no nível simbólico de representação do que é ser indígena ou branco, homem ou mulher, sobre o desenvolvimento, entre outros. Ou seja, o rompimento dos estereótipos que determinam as relações entre as pessoas, nas diferentes manifestações do político. As relações geradas são construções sociais que têm relação com o poder que exercem determinados grupos sobre outros. O nível institucional e individual é refletido no nível simbólico, tudo o que se pode fazer em relação a projetos e iniciativas fica na superfície. 
A tarefa de desconstrução da história e o repensar desta a partir das comunidades indígenas permitirá a possibilidade de repensar e fomentar projetos de vida. É transformadora a possibilidade de contar as histórias pessoais e comunitárias, frente às grandes narrativas que nos paralisam no estereótipo e justificam as relações de exclusão, e influenciam nas opressões que se reproduzem, como a naturalização de que os indígenas não podem criar um software próprio ou narrativas desenhadas em suas próprias cosmovivências (BUSTILLOS, 2004).

A NOTIMIA - Agencia de Noticias de Mujeres Indígenas y Afrodescendientes - surge como uma iniciativa da Alianza de Mujeres Indígenas de Centroamérica y México que, depois de 2013, a partir do trabalho de organização de certificação para a liderança de mulheres indígenas, vê que é importante fortalecer o trabalho de mulheres comunicadoras com o uso das TICs. A Agência realizou três encontros nos anos de 2014, 2015 e 2016, com uma participação total de 204 mulheres. Após estes encontros, as mulheres comunicadoras propõem a criação da Agência de Notícias, que parte da reação sobre a invisibilidade midiática sobre os povos indígenas nos veículos de informação massiva, com o propósito de informar e formar comunicadoras dos povos indígenas e afrodescendentes no uso e manejo das novas tecnologias com um sentido social, político, cultural e de meio ambiente, assinalando os direitos humanos, o gênero e a interculturalidade. O objetivo é ser uma agência de notícias de mulheres indígenas e afrodescendentes, organizadas em rede de comunicadoras latino-americanas, líderes em cobertura internacional, que transmite informações a meios próprios comunitários, locais e nacionais sobre povos e mulheres indígenas a partir das comunidades e povos originários, e em seus respectivos idiomas.

Em abril de 2017 foi realizado o lançamento de NOTIMIA, na Cidade do México, e na 16a sessão do Fórum Permanente para as Questões Indígenas, em Nova lorque, incluída como ação da celebração do decênio da Declaração das Nações Unidas dos Direitos dos Povos Indígenas (2007-2017). ${ }^{3}$ A agência se encarrega de organizar pela primeira vez a zona de meios indígenas, realiza entrevistas e painéis transmitidos ao vivo, pelo sítio oficial na internet, e realiza a cobertura do evento, a partir de grupos e pessoas da sociedade civil que comentam e compartilham suas experiências pessoais e grupais ao mundo. Em janeiro de 2018, a agência se constituiu como uma rede com personalidade jurídica e está traçando seu plano de ação.

\title{
Conclusões
}

As mobilizações dessas mulheres, além de atuarem com protagonismo no registro e salvaguarda de suas memórias sociais e transmitirem conhecimentos, contribuem ativamente para a efetivação dos seus direitos humanos. E o uso de recursos hipermidiáticos é estratégico nessa empreitada. Toda esta movimentação trouxe um empoderamento intransitivo, que não depende de complementos ou assistência perpétua de terceiros. Sob o olhar do feminismo decolonial, apresenta uma relação com vários outros movimentos de feminismo indígena instaurados pela América Latina.

Diferentemente do feminismo hegemônico, que é universalizante e reforça a colonialidade, com questionamentos que não englobam todos os grupos de mulheres, o feminismo decolonial trata de outras demandas, por se concentrar na intersecção entre gênero, raça e classe - invisíveis pelos próprios fenômenos de controle das informações massivas e seus interesses políticos. E que assim, contando com possíveis trocas epistemológicas entre essas vivências e privilegiando os saberes e epistemologias do Sul, possamos viver e aprender com o emancipatório feminismo decolonial, autônomo e dinâmico, estando aproximadas na medida em que houver disposição em diálogos verdadeiramente horizontais e interepistêmicos.

A poeta innu Rita Mitsukuhu resume com clareza a vivência e aprendizagem como mulheres e povos indígenas que habitamos nesse planeta:

\author{
A Linha da Memória \\ Meu povo escrevia caminhando, \\ Meu povo escrevia na linha da memória, \\ Desta forma sua bagagem era menos pesada \\ Já que tinha uma imensa biblioteca com ele, \\ Milhões de livros \\ Dispersos pelo território inuíte, \\ Das enciclopédias de rios
}

\footnotetext{
${ }^{3}$ A Declaração das Nações Unidas dos Direitos dos Povos Indígenas, adotada pela Assembleia Geral da ONU em 13 de setembro de 2007, estipula diretrizes universais de padrões mínimos de sobrevivência para a dignidade e o bemestar dos povos indígenas do mundo. É o instrumento internacional mais amplo sobre os direitos coletivos dos povos indígenas, incluindo os direitos à cultura, autodeterminação e a terras tradicionais (ONU, Organização das Nações Unidas. Declaração das Nações Unidas dos Direitos dos Povos Indígenas. Nova lorque: ONU, 2007).
} 
Dos dicionários de montanhas

De geografia de bosques

Cada linha que se escrevia

Era para guardar sua memória desperta

Seu espírito vivo e seu coração leve.

\section{Referências}

ALMEIDA, Júlia. "Geopolíticas e descolonização do conhecimento". In: SEMINÁRIO NACIONAL DA PÓS-GRADUAÇÃO EM CIÊNCIAS SOCIAIS - UFES, n. 1, Vitória. Anais do Seminário Nacional da PósGraduação em Ciências Sociais. v. 1, 2011. p. 1-10.

ATRIA. Kennisinstituut voor enmancipatie en vrouwengeschiedenis. KNOW HOW CONFERENCE. Amsterdam, Mexico D. F., 1998. Disponível em http://www.atria.nl e http://knowhowcommunity.org. Acesso em 20/10/2006.

BHABHA, Homi K. O Local da Cultura. Belo Horizonte: EDUFMG, 2003.

BUSTILLOS, Nidia. TICs para el empoderamiento de las mujeres indígenas. 2002. Tese (Gestão da Informação e Comunicação) - Hogeschool van Amsterdam.

BUSTILLOS, Nidia. Tambos como espacios de poder comunal: del camino imperial incaico a la autopista electrónica. 2004. Dissertação (Mestrado em Estudos para o Desenvolvimento e Interculturalidade) - Instituto Universitario de Estudios de Desarrollo, Genebra.

CANDAU, Vera. "Direitos humanos, educação e interculturalidade: as tensões entre igualdade e diferença". Revista Brasileira de Educação, v. 13, n. 37, p. 45-57, 1998.

CASTELLS, Manuel. La era de la información: economía, sociedad y cultura. La sociedad red. Madrid: Alianza Editorial, 1997.

CASTELLS, Manuel. La era de la información: economía, sociedad y cultura. El poder de la identidad. Madrid: Alianza Editorial, 1998a.

CASTELLS, Manuel. La era de la información: economía, sociedad y cultura. Fin del mileni. Madrid: Alianza Editorial, 1998b.

CASTRO-GÓMEZ, Santiago. "Le chapitre manquant d’Empire". Multitudes, n. 26, p. 28-49, 2006.

DIAS, Letícia Otero. "O feminismo decolonial de Maria Lugones." In: ENCONTRO DE ENSINO, PESQUISA E EXTENSÃO, UFGD, 8, 2014, Dourados. Anais do Encontro de Ensino, Pesquisa e Extensão. Dourados, 2014. p. 1-16.

HAWTHORNE, Susan. "Connectivity: cultural practices of the powerful or subversion from the margins". In: HAWTHORNE, Susan; KLEIN, Renate. Cyberfeminism. Melbourne: Spinifex Press, 1999. p. 119-133.

INAYATULLAH, Sohail S.; MILOJEVIC, Ivana. "Exclusion and communication in the information era". In: HARCOURT, Wendy. Women @internet: creating new cultures in cyberspace. London and New York: Zed Books, 1999. p. 76-88.

LUGONES, Maria. "Subjetividad esclava, colonialidad de género, marginalidad y opresiones múltiples". Pensando los feminismos en Bolivia, p. 129-140, fevereiro 2012. (Serie Foros)

LUHMANN, Niklas. Poder. Barcelona: Antropos, 1995.

McLAREN, Peter. Multiculturalismo crítico. São Paulo: Cortez, 1997.

MIRANDA, Sergio González. "Interculturalidad y Globalización: el caso de los Aymaras de Tarapacá". Revista de Ciencias Sociales, n. 9, 1999.

MONROE, Javier; ARENAS, Fabrício. Educación intercultural en la Sierra del Perú. Lima: CCTA, 2003.

ONU. NACIONES UNIDAS Y UNIÓN INTERNACIONAL DE TELECOMUNICACIONES. Declaración de Principios. In: Cumbre Mundial sobre la sociedad de la información. Genebra: ONU, 2003. Disponível em www.itu.int. Acesso em 03/05/2017.

ONIC. Organización Nacional Indígena de Colombia. In: TERCER ENCUENTRO NACIONAL DE MUJERES INDÍGENAS. Bogotá: Asociación Alemana para la Cooperación en la Educación Superior, 1994. 
ORTIZ, Renato. "Cultura, Modernidad e identidades". Nueva Sociedad, n. 137, p. 17-23, 1995.

REED, Diane. "La mujer indígena se hace cargo de su destino". In: CUARTA CONFERENCIA MUNDIAL SOBRE LA MUJER. 4, 1995, Beijing. Organización de las Naciones Unidas. Disponível em http:// www.un.org/spanish/conferences/mujer.htm. Acesso em 17/04/2016.

SANTOS, Boaventura de Sousa. "Direitos humanos: o desafio da interculturalidade". Direitos Humanos, v. 2, p. 11-18, junho 2009.

TORRES, Georgina Méndez. "Miradas de género de las mujeres indígenas en Ecuador, Colombia y México". In: PEQUEÑO, Andrea. Participación y políticas de mujeres indígenas en contextos latinoamericanos recientes. Buenos Aires: FLACSO, 2009. p. 53-72.

Lizia de Oliveira Carvalho (lizia.ocarvalho@gmail.com) é mestre em Direitos Humanos pela Universidade Federal de Goiás, possui graduação em Letras Português/Inglês pela UEG (2007) e cursa bacharelado em Direito pela Universidade Federal de Goiás. É mestra pelo Programa de Pós-Graduação Interdisciplinar em Direitos Humanos do PPGIDH/UFG em Goiânia, Goiás, Brasil. Atua principalmente nos seguintes temas: direitos humanos, feminismo decolonial, feminismo negro, feminismo indígena. É integrante da REDESSAN - Rede de Mulheres Negras para Soberania e Segurança Alimentar e Nutricional e colaboradora da NOTIMIA - Agência de Notícias de Mulheres Indígenas e Afrodescendentes.

Nidia Rosmery Bustillos Rodriguez (n_bustillos@yahoo.es) é mestra em Interculturalidade e Globalização pelo International Institute for Development Studies (IUED). Tem mestrado em Estudos para o Desenvolvimento e Interculturalidade no Instituto Universitário de Estudos para o Desenvolvimento em Genebra, Suíça. Licencm, na Holanda. É membra de NOTIMIA - Agência de Notícias de Mulheres Indígenas e Afrodescendentes e responsável pelo empreendimento GaiaTerra (Cochabamba, Departamento de Cochabamba, Bolívia).

\section{COMO CITAR ESSE ARTIGO DE ACORDO COM AS NORMAS DA REVISTA}

CARVALHO, Lizia; BUSTILLOS, Nidia. "Comunicadoras Indígenas e Afrodescendentes LatinoAmericanas: Sororidade e Identidades". Revista Estudos Feministas, Florianópolis, v. 27, n. 1, e59001, 2019.

\section{CONTRIBUIÇÃO DE AUTORIA}

Concepção, coleta e análise de dados, realização de entrevistas, elaboração do manuscrito e redação, discussão de resultados por ambas as autoras.

\section{FINANCIAMENTO}

Na época da escrita, Lizia de Oliveira Carvalho era bolsista da Capes de mestrado.

\section{CONSENTIMENTO DE USO DE IMAGEM}

Não se aplica

APROVAÇÃO DE COMITÊ DE ÉTICA EM PESQUISA

Não se aplica

\section{CONFLITO DE INTERESSES}

Não se aplica

\section{LICENÇA DE USO}

Este artigo está licenciado sob a Licença Creative Commons CC-BY. Com essa licença você pode compartilhar, adaptar, criar para qualquer fim, desde que atribua a autoria da obra. 


\section{HISTÓRICO}

Recebido em 04/09/2018

Aprovado em 07/09/2018 